\title{
Mathematical art
}

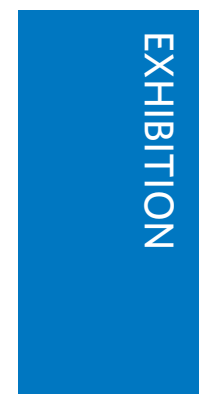

In a former fish market, now exhibition hall, a quote invites the visitor to attempt the absurd in order to achieve the impossible. The maze of dark rooms that follows takes the visitor on an adventure through optical illusion, fantastical cities and eerie animal tessellations. If you have ever wondered what a looped staircase that goes up and down without ever taking you any higher might look like, the M. C. Escher exhibition at Salone degli Incanti in Trieste, Italy is where you can find the answer.

The exhibition features a large collection of works which give a good sense of how Escher's art developed. His early woodcuts of scenes from the Bible already have a distinctive style with echoes of Hokusai's prints, one of which allegedly hung in Escher's family home. This style is further developed in a series of prints depicting small fairytale-like Italian towns. These drawings are very realistic (photographs of the actual towns are provided for comparison) and oddly unsettling at the same time. The feeling one gets is of a world very similar to ours, yet one that is more likely inhabited by magical creatures. In these early works, we can already see Escher developing the skill of making the shapes in his drawings look three-dimensional and creating images that should be realistic yet are impossible - key features of his better-known works.

The following rooms display Escher's tessellations and metamorphosis series. The canvases are covered with intertwining animals that transform into other animals and shapes leaving no empty spaces in between. This is where mathematical elements start emerging in his artwork and indeed Escher was inspired by the tiles of Alhambra that he saw on a trip. These led him to develop a classification of symmetries of his own.

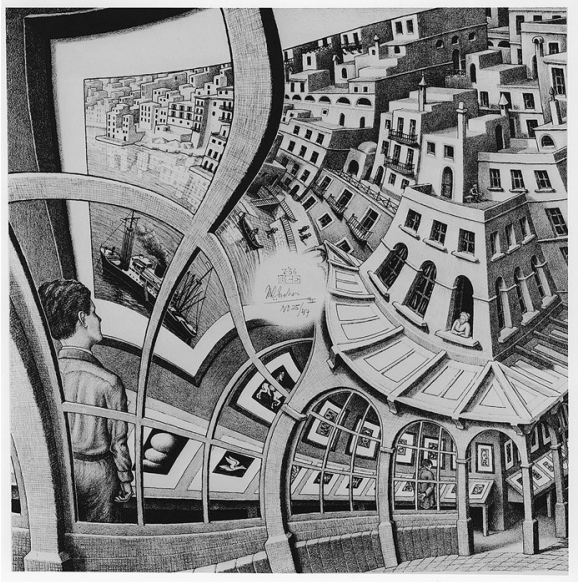

The original of M. C. Escher's Print Gallery. The centre part was recently completed by Hendrik Lenstra. Credit: M. C. Escher's Print Gallery (C) 2020 The M. C. Escher Company - The Netherlands. All rights reserved. https://www. mcescher.com.

Despite never having any formal training, Escher had a remarkable mathematical intuition. The regularity and symmetry of Escher's work attracted the attention of the mathematical community. Unusually for an artist, it was a scientific conference that brought Escher notoriety. He exhibited his work in Amsterdam alongside the annual International Congress of Mathematicians in 1954. There he met scientists with whom he continued to exchange ideas for years, and this influenced his work. The mathematical physicist Roger Penrose was inspired by the exhibition to create an 'impossible staircase' in which one can walk up and down in a loop without ever going any higher. He then shared this impossible object with Escher who drew his own version in the work Ascending and Descending.

In Print Gallery (pictured), Escher depicts a painting which seamlessly transforms into the view of the surrounding town. Escher allegedly hoped for the image to repeat infinitely but left the centre of the image empty. Fifty years later mathematician Hendrik Lenstra and his colleagues from the University of Leiden figured out how to correctly create this illusion using elliptic curve theory and conformal maps and completed the drawing (https://go.nature. com/2xuhmQ4).

Escher's impossible constructions make one wonder how a picture that seems to correctly follow the rules of perspective could still appear so absurd. It is easy to spend a long time gazing at these prints trying to imagine what it would be like to endlessly walk up and down a neverending staircase. It is helpful then that the exhibition provides interactive spaces where the visitor can experience optical illusion for themselves. The illusion of infinitely repeating images is aided by a room covered in mirrors with hanging geometrical shapes which have an effect similar to the Infinity Mirror Rooms by Yayoi Kusama. In another room visitors can be amused by making themselves look much bigger than a fellow visitor.

Those who have never appreciated the beauty of geometric structures or topological objects will have their curiosity tickled and might start seeing polyhedra and tilings in a new light. The more mathematically minded visitors will marvel at how the rules of geometry, symmetry and perspective could be so artfully exploited to create fantastical and impossible-looking structures. The perfect mixture of art and mathematics, this exquisitely curated exhibition will captivate visitors with all sorts of interests.

Escher is at Salone degli Incanti in Trieste, Italy from December 2019 to June 2020.

Reviewed by Elizaveta Dubrovina

Locum Senior Editor, Nature Physics.

e-mail:elizaveta.dubrovina@nature.com

Published online: 6 April 2020

https://doi.org/10.1038/s41567-020-0869-X 